\title{
Frequency and Predictors of Sleep Disorders in Undergraduate Medical Students
}

\author{
Saima Zainab, Rafiq Ahmed Soomro, Aneeta Khoso, Nimra Aziz Qazi, Saroop Siddiqui
}

\begin{abstract}
OBJECTIVE: To assess frequency of sleep disorders among the medical students and to explore the association between different predictors and sleep disorders among the medical students.

METHODOLOGY: This cross-sectional study was conducted from September 2016 to December 2017 at Liaquat National Medical College Karachi, Pakistan. The study used $31 \%$ as prevalence of poor quality of sleep among medical students in Pakistan as identified in a previous research and $95 \%$ confidence level. The largest sample size calculated was $n=329$. To adjust for the $10 \%$ expected non-response from some students, the final sample size was increased to 360 medical students. Non-probability purposive sampling technique was employed to recruit medical students. Students having systemic diseases, clinically diagnosed psychiatric problems and addiction, or those who refused to be part of the research were excluded. Internationally validated questionnaires were used for data collection which included Insomnia Severity Index, Depression Anxiety Stress Scale, Berlin Questionnaire and Epworth Sleepiness Scale.

RESULTS: Mean age of students was $\mathbf{2 1 . 9 8}$ years. Majority of them were females. Over $50 \%$ of students used internet more than 4 hours daily. One-third $36.3 \%$ (131) medical students obtained higher than normal scores on stress scale and $46 \%$ (167) on anxiety scale. The frequencies of students on risk of sleep disorders were as; day-time sleepiness $34 \%$, obstructive sleep apnea $20 \%$ and insomnia $17 \%$. The predictors of sleep disorders were male gender, excessive internet use and anxiety.

CONCLUSION: The considerable frequency of medical students is at risk of developing sleep disorders. The likelihood is more for male students and excess internet use.
\end{abstract}

KEYWORDS: Sleep disorders, Predictors, Undergraduate, Medical students

This article may be cited as: Zainab S, Soomro RA, Khoso A, Qazi NA, Siddiqui S. Frequency and Predictors of Sleep Disorders in Undergraduate Medical Students. J Liaquat Uni Med Health Sci. 2020;19(02):109-15. doi: 10.22442/jlumhs.201920672

\section{INTRODUCTION}

Over the last three decades a significant change has been observed in the sleep pattern of student ${ }^{1}$. There has been an increase in the frequency of students suffering from sleep disorders, resulting in a drop in the quality and duration of sleep ${ }^{2,3}$. Medical students, in particular, have more sleep disorders. They have to encounter the extensive medical curriculum and demanding academic activities. Frequent assessments, long working hours, varying clinical rotations and lack of leisure time make sleep a lower priority for these students ${ }^{4}$.

In addition to it, the day to day exposure of human sufferings and deaths in their clinical settings predispose medical students to higher burden of stress and anxiety ${ }^{5}$. Previous studies report a higher prevalence of stress and anxiety among medical students compared to the general population ${ }^{6,7}$. Prevalence of stress among medical students was reported to be $47 \%$ in $\mathrm{Brazil}^{8}, 60 \%$ in $\mathrm{Egypt}^{9}$ and $63 \%$ in Saudi Arabia ${ }^{10}$. Rizvi F $2015^{11}$ accounted the prevalence of stress and anxiety among Pakistani medical students as $50 \%$ and $74.2 \%$, respectively. Stress and anxiety among these students results in various sleep disorders which may lead to negative outcomes on their academic performances.

Sleep disorders are also strongly linked with lifestyle practices including excessive use of mobile phones and internet for socializing or learning purposes ${ }^{12}$. Over use of technology impede college students from obtaining sufficient sleep $^{13}$, subsequently increasing the risk of insomnia, daytime sleepiness and poor sleep quality ${ }^{14,15}$. There are serious consequences of sleep disorders among the students. The risk of acquiring various psychiatric illnesses and medical problems including hypertension, obesity, insulin resistance and diabetes are high in later life ${ }^{1,16}$. There is a need to timely identify the students at a risk of developing sleep disorders and create awareness regarding good sleep practices. This would result in directing their potentials towards highest level of knowledge and enabling them to flourish in their academic activities.

In Pakistan, previous literature has identified poor quality of sleep among medical students ${ }^{17}$ and the effect of sleep pattern on academic achievements ${ }^{18}$. However, there is inadequacy of literature regarding the specific types and the possible predictors of sleep disorders among medical students, which gave way to explore such associations, through a cross sectional survey. The aim of this study was to identify the 
medical students at risk of developing sleep disorders namely insomnia, obstructive sleep apnea and day time sleepiness. Furthermore, it also aimed to to explore the associations between different predictors and sleep disorders among the medical students.

\section{METHODOLOGY}

This cross-sectional study was conducted from September 2016 to December 2017. The study participants comprised of undergraduate medical students enrolled in first to final years of the five-year Bachelor of Medicine and Bachelor of Surgery (MBBS) degree program at Liaquat National Medical College Karachi, Pakistan. Open Epi software version 3.01 was used for sample size calculation. The study used $31 \%$ as prevalence of poor quality of sleep among medical students in Pakistan as identified in a previous research ${ }^{19}$ and $95 \%$ confidence level. The largest sample size calculated was $n=329$. To adjust for the $10 \%$ expected non-response from some students, the final sample size was increased to 360 medical students. Non-probability purposive sampling technique was employed to recruit medical students. Students having systemic diseases, clinically diagnosed psychiatric problems and addiction, or those who refused to be part of the research were excluded.

The data was collected using a structured questionnaire administered by trained data collectors. Four internationally validated and reliable questionnaires, namely the Berlin Questionnaire (BQ), the Insomnia Severity Index (ISI), the Depression Anxiety Stress Scales (DASS) and the Epworth Sleepiness Scale (ESS) were employed to identify the students at risk of developing the above-mentioned sleep disorders. The socio-demographic characteristics of students and their lifestyle were recorded in a separate questionnaire. Self-reported internet use and academic performance wereas recorded. It took around 20 to 25 minutes to complete an interview. The nature and purpose of the study were explained to participants in detail. A written informed consent was taken from the study participants. The students who were identified at risk of any of the sleep disorders were referred to consultants.

Considering descriptive statistics, for continuous type of socio-demographic variables, we used mean and standard deviations. Frequencies with percentages were used for categorical variables. We used cross tabs in order to assess the percentages of students who had stress and anxiety, and were at risk of hypersomnia, insomnia and apnea. In order to address the confounders in the study, univariate and multivariate logistic regression analysis was employed. This helped us in determining the unadjusted and adjusted relationships between predictor (age, gender, education, stress, anxiety, internet use and academic performance) and outcome variables (Sleep disorders i.e. insomnia, day-time sleepiness and obstructive sleep apnea). The p-value of $<0.05$ was considered to be statistically significant. SPSS version 22 software was used for data analysis. The protocol of the study was approved by Ethical Review Committee of Liaquat National Hospital and Medical College Karachi.

Anxiety, stress, insomnia, obstructive sleep apnea and day-time sleepiness were defined by using the following standard questionnaires:

\section{Anxiety and Stress:}

The Depression, Stress and Anxiety scale (DASS) was used to identify the students at risk of stress and anxiety. It was a 42-item questionnaire designed to measure depression, anxiety and stress. Each of the three scales contains 14 items, divided into subscales of 2-5 items with similar content. Only the Anxiety and Stress scales of this questionnaire were used for this study. Scores of anxiety and stress were calculated by summing the scores for the relevant items ${ }^{20}$. The following cut-off scores were used for anxiety: normal $0-3$, mild 4-5, moderate 7-10, severe $11-13$ and extremely severe 10+; and the cutoff scores for stress were: normal $0-7$, mild $8-9$, moderate $10-12$, severe 13-16 and extremely severe $17+$.

\section{Insomnia:}

Insomnia Severity Index (ISI) was used to identify the students at risk of developing insomnia. The ISI is a 7item self-report questionnaire. The 5-point likert scale is used to rate each item ( 0 to 4 , where 0 indicates no problem and 4 indicates very severe problem), yielding a total score ranging from 0 to 28 . Clinically significant insomnia was detected when the total score was $>142^{21}$.

\section{Obstructive sleep apnea:}

Berlin Questionnaire (BQ) was used as a screening tool for Obstructive sleep apnea. Students who had a positive score on two or more categories were considered at high risk for obstructive sleep apnea ${ }^{22}$.

\section{Day-time sleepiness:}

The Epworth Sleepiness Scale (ESS) was used as a screening tool of day-time sleepiness. A sum of 9 or more scores on this scale was specified as significant day-time sleepiness ${ }^{23}$.

\section{RESULTS}

The mean age of the undergraduate medical students was 21.98 years $(S D=1.7$ years) and a majority $(249)$ of them were females (69\%). Almost $58 \%$ (210) of the students were using internet for more than 4 hours daily, with slight difference between female and male students (60\% vs. $56 \%$, respectively). Over one-third (131) of the students obtained higher scores on stress scale. The female students had higher stress scores than males $(37.8 \%$ vs. $32.3 \%$ respectively). The percentage of students whose scores were above 
normal range on anxiety scale was $46.4 \%$, of which $17 \%$ had severe anxiety. More than two-thirds (252/ $70 \%$ ) of the undergraduate medical students perceived that internet usage was affecting their academic performance. Overall, $34 \%$ (124) of the students scored far above the normal range for daytime sleepiness, $20 \%$ (74) for obstructive sleep apnea and $17 \%$ (62) for insomnia (Table I).

Hypersomnia among the Medical students having anxiety and stress. Around $47 \%$ of the students having anxiety were at risk of hypersomnia. Similarly, $47 \%$ of the students having stress had risk of hypersomnia.

Apnea among the Medical students having anxiety and stress. Around $30 \%$ of students who had anxiety were at risk of having apnea, while $25 \%$ of students having stress had a risk of having apnea.

Insomnia among the Medical students having anxiety and stress, $25 \%$ of the students who had anxiety were at risk of having insomnia, while $28 \%$ of the students who were stressed had a risk of anxiety.

Table II shows the Logistic Regression analysis on association of obstructive sleep apnea with independent variables. On univariate analysis, age, gender, internet use, high scores on stress and anxiety scale were found to be significantly associated ( $p$-value $<0.05$ ) with obstructive sleep apnea.

Multivariable logistic regression analysis showed $37 \%$ increased risk of having obstructive sleep apnea, with one year increase in the age of the student (OR: 1.37; $95 \% \mathrm{Cl}: 1.01-1.85$ ). Male students had 3.5 times higher risk of developing obstructive sleep apnea $(95 \% \mathrm{Cl}: 1.85-6.66)$. Students using internet for 4 to 8 hours daily were more likely to have obstructive sleep apnea (OR: 2.4, 95\% Cl: 1.14 - 5.08). In addition, a strong association was observed between obstructive sleep apnea and mild anxiety (OR: $3.44,95 \% \mathrm{Cl}$ : 1.47- 8.07).

Table III shows the logistic regression analysis on association of independent factors with day-time sleepiness. The mutivariable model showed a significant association between extremely severe anxiety (OR: 3.58, 95\% Cl: $1.14-11.26$ ) and day-time sleepiness. The students in third year of undergraduate medical education had 3.1 times higher risk of day-time sleepiness as compared to their fellows. Also, the students who perceived that internet use is affecting their academic performance showed a strong association with day-time sleepiness. Table IV shows the logistic regression analysis on association of insomnia with the independent factors. The multivariate regression model showed the considerable impact of more than 12 hours daily internet use (OR: $5.20,95 \% \mathrm{Cl}$ : $1.66-16.26$ ) on insomnia. Furthermore, the students who perceived that their academic performance is frequently affected by internet use were 5 times more likely to suffer from insomnia (95\% Cl: $1.69-14.82)$.
TABLE I: SOCIO-DEMOGRAPHIC CHARACTERISTICS OF UNDERGRADUATE MEDICAL STUDENTS IN KARACHI, PAKISTAN $(n=360)$

\begin{tabular}{|c|c|}
\hline Variable & $n(\%)$ \\
\hline Age (years) Mean (SD) ${ }^{a}$ & $21.98(1.72)$ \\
\hline $\begin{array}{l}\text { Gender } \\
\text { Male } \\
\text { Female }\end{array}$ & $\begin{array}{l}111(30.8 \%) \\
249(69.2 \%)\end{array}$ \\
\hline $\begin{array}{l}\text { Educational year in medical college } \\
\text { First } \\
\text { Second } \\
\text { Third } \\
\text { Fourth } \\
\text { Fifth }\end{array}$ & $\begin{array}{r}31(8.6 \%) \\
79(21.9 \%) \\
84(23.3 \%) \\
79(21.9 \%) \\
87(24.2 \%)\end{array}$ \\
\hline
\end{tabular}

\begin{tabular}{lr}
\hline Time spent on internet use/ day & \\
$<4$ hours & $150(41.7 \%)$ \\
$4-8$ hours & $139(38.6 \%)$ \\
$>8-12$ hours & $49(13.6 \%)$ \\
$>12$ hours & $22(6.1 \%)$
\end{tabular}

Stress score (DASS)

Normal

Mild

$229(63.6 \%)$

Moderate

$53(14.7 \%)$

Severe

$52(14.4 \%)$

Extremely Severe

$17(4.7 \%)$

$9(2.5 \%)$

\begin{tabular}{lr}
\hline Anxiety score (DASS) & \\
Normal & $193(53.6 \%)$ \\
Mild & $54(15 \%)$ \\
Moderate & $50(13.9 \%)$ \\
Severe & $32(8.9 \%)$ \\
Extremely Severe & $31(8.6 \%)$ \\
\hline Obstructive Sleep Apnea & \\
Yes & $74(20.6 \%)$ \\
No & $286(79.4 \%)$ \\
\hline Insomnia (ISI scale) & \\
Yes & $62(17.2 \%)$ \\
No & $298(82.8 \%)$ \\
\hline Day-time sleepiness (ESS scale) & \\
Yes & $124(34.4 \%)$ \\
No & $236(65.6 \%)$ \\
\hline Self perceived effect on academic & \\
performance & \\
Not at all & $108(30 \%)$ \\
Sometimes & $131(36.4 \%)$ \\
Frequently & $57(15.8 \%)$ \\
Very frequently & $64(17.8 \%)$ \\
\hline
\end{tabular}

$a=S D=$ Standard Deviation 
Frequency and Predictors of Sleep Disorders

TABLE II: LOGISTIC REGRESSION ANALYSIS FOR THE ASSOCIATION OF OBSTRUCTIVE SLEEP APNEA WITH INDEPENDENT VARIABLES

\begin{tabular}{lll}
\hline \multicolumn{3}{c}{ Obstructive Sleep apnea OR $(\mathbf{9 5 \%} \mathbf{C I})^{\alpha}$} \\
\hline \multicolumn{1}{c}{ Unadjusted } & \multicolumn{1}{c}{ Adjusted } \\
\hline Age (years) & $1.18(1.02-1.37)^{*}$ & $1.37(1.01-1.85)^{*}$ \\
\hline Gender & \\
Female & 1 & \\
Male & $3.08(1.81-5.22)^{* * \star}$ & $3.52(1.85-6.66)^{* \star *}$ \\
\hline Medical college & & \\
year & & 1 \\
First & 1 & $1.19(0.26-5.09)$ \\
Second & $1.20(0.35-4.08)$ & $2.61(056-12.14)$ \\
Third & $2.86(0.90-9.02)$ & $0.69(0.12-3.71)$ \\
Fourth & $1.45(0.43-4.8)$ & $0.71(0.10-4.65)$ \\
Fifth & $1.88(0.58-6.05)$ & \\
\hline
\end{tabular}

\begin{tabular}{lll}
\hline $\begin{array}{l}\text { Number of hours } \\
\text { students spent } \\
\text { on internet }\end{array}$ & & \\
$\begin{array}{l}\text { Less than } 4 \text { hours } \\
4 \text { to } 8 \text { hours }\end{array}$ & 1 & 1 \\
8 to 12 hours & $2.06(1.10-3.84)^{*}$ & $2.41(1.14-5.08)^{*}$ \\
More than 12 & $4.75(1.25-6.04)^{*}$ & $1.74(0.63-4.79)$ \\
hours & & $2.92(0.88-9.61)$ \\
\hline Stress level & & \\
Nil & 1 & 1 \\
Mild & $0.93(0.42-2.07)$ & $0.55(0.20-1.47)$ \\
Moderate & $1.23(0.58-2.59)$ & $0.21(0.06-0.74)^{*}$ \\
Severe & $5.15(1.87-14.17)^{* *}$ & $0.75(0.15-3.73)$ \\
Extremely severe & $3.66(0.94-14.25)$ & $0.22(0.02-1.77)$ \\
\hline Anxiety level & & \\
Nil & 1 & 1 \\
Mild & $2.7(1.3-5.63)^{* *}$ & $3.44(1.47-8.07)^{* *}$ \\
Moderate & $1.14(0.46-2.83)$ & $1.38(0.45-4.20)$ \\
Severe & $1.97(0.77-5.05)$ & $1.69(0.47-5.99)$ \\
Extremely severe & 14.78 & 32.01 \\
& $(6.22-35.15)^{* * *}$ & $(7.45-137.42)^{* * *}$ \\
\hline
\end{tabular}

\begin{tabular}{|c|c|c|}
\hline \multicolumn{3}{|l|}{$\begin{array}{l}\text { Self perceived } \\
\text { effect on } \\
\text { academic } \\
\text { performance }\end{array}$} \\
\hline Not at all & 1 & 1 \\
\hline Sometimes & $1.39(0.68-2.80)$ & $1.09(0.48-2.47)$ \\
\hline Frequently & $2.21(0.99-4.94)$ & $1.99(0.72-5.48)$ \\
\hline Very frequently & $2.81(1.31-6.02)^{* *}$ & $1.68(0.59-4.77)$ \\
\hline \multicolumn{3}{|c|}{$\begin{array}{l}{ }_{\alpha}^{*} p \text {-value }=<0.05,{ }_{\alpha}^{* *} p \text {-value }=<0.01, \stackrel{ }{* * *} \text {-value }=<0.001, \\
{ }^{*} O R=\text { odds ratio, } \mathrm{Cl}=\text { confidence interval }\end{array}$} \\
\hline
\end{tabular}

The study sample comprised of the students from all five years of undergraduate medical college. Almost $70 \%$ of the students were females. This increasing induction of female students in medical colleges has also been observed by Surani $A A$ et $\mathrm{al}^{19}$. Over the years it is a remarkable observation in Pakistan that the female students are performing better in
TABLE III: LOGISTIC REGRESSION ANALYSIS FOR THE ASSOCIATION OF DAY-TIME SLEEPINESS WITH INDEPENDENT VARIABLES

\begin{tabular}{|c|c|c|}
\hline \multicolumn{3}{|c|}{ Day-time sleepiness OR $(95 \% \mathrm{CI})^{\alpha}$} \\
\hline & Unadjusted & Adjusted \\
\hline Age (years) & $0.93(0.82-1.06)$ & $0.87(0.68-1.12)$ \\
\hline $\begin{array}{l}\text { Gender } \\
\text { Female } \\
\text { Male }\end{array}$ & $\begin{array}{l}1 \\
1.10(0.691 .76)\end{array}$ & $1.23(0.71-2.13)$ \\
\hline $\begin{array}{l}\text { Medical college } \\
\text { year } \\
\text { First } \\
\text { Second } \\
\text { Third } \\
\text { Fourth } \\
\text { Fifth }\end{array}$ & $\begin{array}{l}1 \\
1.87(0.73-4.67) \\
2.49(1.00-6.2) \\
0.91(0.35-2.3) \\
1.29(0.51-3.25)\end{array}$ & $\begin{array}{l}1 \\
1.99(0.73-5.44) \\
3.14(1.03-9.61) \\
1.71(0.49-6.13) \\
3.26(0.76-13.93)\end{array}$ \\
\hline $\begin{array}{l}\text { Number of hours } \\
\text { students spent } \\
\text { on internet } \\
\text { Less than } 4 \text { hours } \\
4 \text { to } 8 \text { hours } \\
8 \text { to } 12 \text { hours } \\
\text { More than } 12 \\
\text { hours }\end{array}$ & $\begin{array}{l}1 \\
1.15(0.70-1.90) \\
1.80(0.92-3.51) \\
4.21(1.65-10.76)^{\text {** }}\end{array}$ & $\begin{array}{l}1 \\
0.96(0.54-1.70) \\
1.02(0.47-2.20) \\
2.39(0.83-6.82)\end{array}$ \\
\hline $\begin{array}{l}\text { Stress level } \\
\text { Nil } \\
\text { Mild } \\
\text { Moderate } \\
\text { Severe } \\
\text { Extremely severe }\end{array}$ & $\begin{array}{l}1 \\
1.91(1.02-3.55)^{*} \\
2.69(1.45-4.99)^{* *} \\
3.03(1.11-8.20)^{*} \\
3.36(0.87-12.94)\end{array}$ & $\begin{array}{l}1 \\
0.98(0.46-2.11) \\
0.84(0.36-1.93) \\
0.62(0.17-2.19) \\
0.54(0.10-2.84)\end{array}$ \\
\hline $\begin{array}{l}\text { Anxiety level } \\
\text { Nil } \\
\text { Mild } \\
\text { Moderate } \\
\text { Severe } \\
\text { Extremely severe }\end{array}$ & $\begin{array}{l}1 \\
1.59(0.83-3.07) \\
2.72(1.42-5.20)^{* *} \\
4.10(1.89-8.90)^{* *} \\
5.06(2.28-11.20)^{* \star *}\end{array}$ & $\begin{array}{l}1 \\
1.18(0.56-2.47) \\
1.66(0.74-3.74) \\
2.29(0.85-6.16) \\
3.58(1.14-1.26)^{*}\end{array}$ \\
\hline $\begin{array}{l}\text { Self perceived } \\
\text { effect on academic } \\
\text { performance } \\
\text { Not at all } \\
\text { Sometimes } \\
\text { Frequently } \\
\text { Very frequently }\end{array}$ & $\begin{array}{l}1 \\
3.4(1.73-6.84)^{* \star \star} \\
10.80(4.92-23.68)_{* \star \star}^{* \star *} \\
8.82(4.12-18.86)^{*}\end{array}$ & $\begin{array}{l}1 \\
3.30(1.60-6.81)^{\star *} \\
9.53(4.03-22.51)^{\star * *} \\
5.85(2.42-14.14)^{* * *}\end{array}$ \\
\hline${ }^{*} \mathrm{p}-\mathrm{V}$ & $\begin{array}{l}<0.01,{ }^{* * *} p-1 \\
\text { ence interval }\end{array}$ & .001 \\
\hline
\end{tabular}

competitive exams and they acquire more seats in degree programs as compared to male students.

This study identified that $58 \%$ of the students were using internet for more than 4 hours daily. There is increased in ownership of smart phones and personal computers among the students. Students frequently get involved in internet-based activities after dinner and late night for online games, social media and 
Saima Zainab, Rafiq Ahmed Soomro, Aneeta Khoso, Nimra Aziz Qazi, Saroop Siddiqui

TABLE IV: LOGISTIC REGRESSION ANALYSIS FOR THE ASSOCIATION OF INSOMNIA WITH INDEPENDENT VARIABLES

\begin{tabular}{|c|c|c|}
\hline \multicolumn{3}{|c|}{ Insomnia OR $(95 \% \mathrm{Cl})^{\alpha}$} \\
\hline & Unadjusted & Adjusted \\
\hline Age (years) & $1.02(0.87-1.19)$ & $1.15(0.83-1.60)$ \\
\hline $\begin{array}{l}\text { Gender } \\
\text { Female } \\
\text { Male }\end{array}$ & $\begin{array}{l}1 \\
1.40(0.79-2.49)\end{array}$ & $\begin{array}{l}1 \\
1.42(0.71-2.83)\end{array}$ \\
\hline $\begin{array}{l}\text { Medical college } \\
\text { year } \\
\text { First } \\
\text { Second } \\
\text { Third } \\
\text { Fourth } \\
\text { Fifth }\end{array}$ & $\begin{array}{l}1 \\
2.95(0.80-10.81) \\
2.19(0.59-8.13) \\
1.20(0.30-4.76) \\
1.94(0.52-7.23)\end{array}$ & $\begin{array}{l}1 \\
2.54(0.60-10.67) \\
1.76(0.33-8.76) \\
0.91(0.15-5.57) \\
1.32(0.17-10.09)\end{array}$ \\
\hline $\begin{array}{l}\text { Number of hours } \\
\text { students spent } \\
\text { on internet } \\
\text { Less than } 4 \text { hours } \\
4 \text { to } 8 \text { hours } \\
8 \text { to } 12 \text { hours } \\
\text { More than } 12 \\
\text { hours }\end{array}$ & $\begin{array}{l}1 \\
1.09(0.55-2.16) \\
1.99(0.87-4.55) \\
9.95(3.75-26.44)^{* \star *}\end{array}$ & $\begin{array}{l}1 \\
1.11(0.51-2.39) \\
1.37(0.53-3.57) \\
5.20(1.66-16.26)^{\text {** }}\end{array}$ \\
\hline $\begin{array}{l}\text { Stress level } \\
\text { Nil } \\
\text { Mild } \\
\text { Moderate } \\
\text { Severe } \\
\text { Extremely severe }\end{array}$ & $\begin{array}{l}1 \\
1.45(0.61-3.42) \\
3.62(1.76-7.45)^{\text {***}} \\
4.45(1.51-13.08)^{\text {** }} \\
28.56(5.62-45.10)^{\text {***}}\end{array}$ & $\begin{array}{l}1 \\
0.79(0.27-2.30) \\
1.77(0.65-4.84) \\
1.24(0.28-5.42) \\
7.18(0.90-17.00)\end{array}$ \\
\hline $\begin{array}{l}\text { Anxiety level } \\
\text { Nil } \\
\text { Mild } \\
\text { Moderate } \\
\text { Severe } \\
\text { Extremely severe }\end{array}$ & $\begin{array}{l}1 \\
0.88(0.31-2.47) \\
3.70(1.73-7.94) \\
1.99(0.73-5.43) \\
9.22(3.97-21.43)^{\star \star \star}\end{array}$ & $\begin{array}{l}1 \\
0.55(0.17-1.77) \\
1.88(0.70-5.03) \\
0.61(0.15-2.43) \\
1.95(0.50-7.57)\end{array}$ \\
\hline
\end{tabular}

Self perceived

effect on academic

performance

Not at all

Sometimes

Frequently

Very frequently

\section{1}

$1.61(0.65-3.97) \quad 1.30(0.48-3.52)$

$2.98(1.12-7.92)^{*} \quad 2.16(0.71-6.60)$

$9.72(4.06-23.28){ }^{* \star *} \quad 5.01(1.69-14.82){ }^{* *}$
${ }^{*} p$-value $=<0.05,{ }^{\star *} p$-value $=<0.01,{ }^{\star \star *} p$-value $=<0.001$, ${ }^{a} \mathrm{OR}=$ odds ratio, $\mathrm{Cl}=$ confidence interval

other related purposes ${ }^{1}$.

The medical students scored high for stress (36\%) and anxiety (46\%) which were, however, lower when compared to the findings of Rizvi F $2015^{11}$. This could be because our study sample comprised of students from a private medical college in contrast to the reported study conducted on students from both private as well as public medical colleges. Students in private medical colleges come across less economical problems and responsibilities as compared to the students of public institutions. Given that they are able to afford the annual and/semester fee and are known to belong to higher socio-economic statuses. Such financial pressures have been identified as the reason of stress and anxiety among students by Altaf $M$ $2013^{24}$.

The study identified $20 \%$ of students were at risk of obstructive sleep apnea, $17 \%$ for insomnia and 34\% for day-time sleepiness. The literature shows that sleep disorders are frequent among medical students $^{16}$. About $40 \%$ of medical students in Pakistan were identified as poor sleepers by Surani $A A$ et $a^{19}$. The previous studies identified the relationship of poor sleep with physical environment, economy and academic grades. Similar to the literature ${ }^{25}$, in this study obstructive sleep apnea was found to be higher among male students.

Almost $33 \%$ of students in this sample reported their academic performance being frequently affected by excessive use of internet. Their poor academic performance was also strongly associated with risk of getting sleep disorders particularly insomnia and day-time sleepiness, similar findings were obtained by Haile YG $2017^{26}$ in Ethiopia. Similar to these findings, previous researchers also mentioned the strong association between increased duration of internet use and sleep disorders ${ }^{27,28}$. Excessive time spent on the internet leads to compromised sleep which ultimately affects the academic performance of students leading to the development of stress and anxiety $^{27}$.

One year increase in the age of the student resulted in a significant increase in obstructive sleep apnea. We found similar results among senior students of third year MBBS having a greater risk of day-time sleepiness. Lifespan changes in sleep quality are multifaceted, which are also dependent on academic and/or clinical responsibilities, as shown in a large survey study of Malaysian medical students ${ }^{28}$. Similarly, sleep and sleepiness was found to be worse for interns and postgraduate trainees, compared to medical students, according to an Indian study ${ }^{29}$.

Multiple studies accessing gender differences in sleep quality have been shown to represent mixed results. In the earlier mentioned Indian study ${ }^{29}$, sleep quality in females was better than in males, much like our study results. However, no significant associations were found between genders and sleep quality in an Iranian study $^{30}$.

\section{Strengths:}

We employed standardized and internationally validated questionnaires to identify the risk of getting stress, anxiety and sleep disorders among medical students. The sample comprised of students from all five years of the MBBS teaching program.

\section{Limitations:}

The study sample was taken from a single medical 
college so the study results cannot be generalized. It is a private medical college where students belong to upper socioeconomic status. Further researches are needed to understand sleep disorders among students belonging to public medical institutions. This study, being cross sectional in design cannot be inferred regarding the causality and temporality between stress, anxiety and sleeps disorders.

\section{CONCLUSION}

Sleep disorders are common among medical students and affect their academic performance. Internet use, stress and anxiety are strongly predictors of sleep disorders. There is a need to educate medical students regarding good sleep habits in order to avoid the development of psychiatric and medical problems in future.

\section{ACKNOWLEDGEMENT}

We would like to thank all students who participated in the study.

Ethical permission: Liaquat National Hospital Karachi No. APP\#0217-2015LNH-ERC, dated 21-05-2015.

Conflict of Interest: There is no conflict of interest.

Funding: There was no any funding agency.

\section{REFERENCES}

1. Royant-Parola $S$, Londe V, Tréhout $S$, Hartley $S$. The use of social media modifies teenagers' sleep -related behavior. Encephale. 2018; 44(4): 321328. doi:10.1016/j.encep. 2017. 03.009.

2. Bhandari PM, Neupane D, Rijal S, Thapa K, Mishra SR, Poudyal AK. Sleep quality, internet addiction and depressive symptoms among undergraduate students in Nepal. BMC Psychiatry. 2017; 17: 106. doi: 10.1186/s12888-017-1275-5.

3. Friedrich A, Schlarb AA. Let's talk about sleep: a systematic review of psychological interventions to improve sleep in college students. J Sleep Res. 2018; 27(1): 4-22. doi: 10.1111/jsr.12568.

4. Shah M, Hasan S, Malik S, Sreeramareddy CT. Perceived stress, sources and severity of stress among medical undergraduates in a Pakistani medical school. BMC Med Educ. 2010; 10: 2. doi: 10.1186/1472-6920-10-2.

5. Dahlin M, Joneborg N, Runeson B. Stress and depression among medical students: a cross-sectional study. Med Educ. 2005; 39(6): 594 -604. doi: 10.1111/j.1365-2929.2005.02176.x

6. Waqas A, Khan S, Sharif W, Khalid U, Ali A. Association of academic stress with sleeping difficulties in medical students of a Pakistani medical school: a cross sectional survey. Sambunjak D, ed. Peer J. 2015; 3: e840. doi:10.7717/peerj.840.

7. Krägeloh CU, Henning MA, Hawken SJ, Zhao Y, Shepherd D, Billington R. Validation of the WHOQOL-BREF quality of life questionnaire for use with medical students. Educ Health (Abingdon). 2011; 24(2): 545.

8. Moutinho IL, Maddalena NC, Roland RK, Lucchetti AL, Tibirica SH, Ezequiel OD, et al. Depression, stress and anxiety in medical students: A cross-sectional comparison between students from different semesters. Rev Assoc Med Bras (1992). 2017; 63(1): 21-28. doi: 10.1590/ 1806-9282.63.01.21.

9. Fawzy M, Hamed SA. Prevalence of psychological stress, depression and anxiety among medical students in Egypt. Psychiatry Res. 2017; 255: 186 -194. doi: 10.1016/j.psychres.2017.05.027

10. Abdulghani HM, AlKanhal AA, Mahmoud ES, Ponnamperuma GG, Alfaris EA. Stress and its effects on medical students: a cross-sectional study at a college of medicine in Saudi Arabia. J Health Popul Nutr. 2011; 29(5): 516-522.

11. Rizvi F, Qureshi A, Rajput AM, Afzal M. Prevalence of depression, anxiety and stress (by DASS scoring system) among medical students in Islamabad, Pakistan. Br J Med Med Res. 2015; 8: 69-75. doi: 10.9734/BJMMR/2015/17193.

12. Saxena $Y$, Abha $S$, Singh $P$. Short Communication mobile usage and sleep patterns among medical students. Indian J Physiol Pharmacol. 2014; 58(1): 100-103.

13. Owens H, Christian B, Polivka B. Sleep behaviors in traditional-age college students: A state of the science review with implications for practice. J Am Assoc Nurse Pract. 2017. 29(11):695-703. doi: 10.1002/2327-6924.12520.

14. Telzer EH, Fuligni AJ, Lieberman MD, Galván A. The effects of poor quality sleep on brain function and risk taking in adolescence. Neuroimage. 2013; 71: 275-283. doi:10.1016/ j.neuroimage. 2013.01.025.

15. Ferreira $C$, Ferreira $H$, Vieira $M J$, Costeira $M$, Branco L, Dias Â, et al. Epidemiology of Internet Use by an Adolescent Population and its Relation with Sleep Habits. Acta Med Port. 2017; 30(7-8): 524-533. doi: 10.20344/amp.8205.

16. Zheng B, Wang K, Pan Z, Li M, Pan Y, Liu T, et al. Associations between dormitory environment/ other factors and sleep quality of medical students. Zhonghua Liu Xing Bing Xue Za Zhi. 2016; 37(3): 348-52. doi: 10.3760/cma.j.issn.0254 -6450.2016 .03 .011 .

17. Bhatti AA, Khan UA, Khan H. Sleep habits of first year and final year medical students. Rawal Med J. 2012; 37(2): 148-51.

18. Ansari W, Raziq MA, Iqbal T, lqbal SA, Tanveer $\mathrm{ZH}$. Effect of changed sleep pattern on academic performance of medical students at Quaid-eAzam medical college Bahawalpur. J Sheikh Zayed Med Coll. 2011; 2(2): 165-7.

19. Surani AA, Zahid S, Surani A, Ali S, Mubeen M, Khan $\mathrm{RH}$. Sleep quality among medical students 
of Karachi, Pakistan. J Pak Med Assoc. 2015; 65 (4): $380-2$.

20. Lovibond SH, Lovibond PF, Psychology Foundation of Australia. Manual for the Depression Anxiety Stress Scales. ( $2^{\text {nd }}$ Ed) Sydney, Psychology Foundation of Australia; 1995.

21. Gagnon C, Belanger L, Ivers H, Morin CM. Validation of the Insomnia Severity Index in primary care. J Am Board Fam Med. 2013; 26(6): 701-10. doi:10.3122/jabfm.2013.06. 130064

22. Thurtell MJ, Bruce BB, Rye DB, Newman NJ, Biousse V. The Berlin questionnaire screens for obstructive sleep apnea in idiopathic intracranial hypertension. J Neuroophthalmol. 2011; 31(4): 316-9. doi: 10.1097/WNO.0b013e31821a4d54.

23. Johns MW. A new method for measuring daytime sleepiness: The Epworth sleepiness scale. Sleep. 1991; 14(6): 540-5.

24. Altaf M, Altaf KF, Iftikhar A, Gohar S, Yusra. Workload and health problems in medical students. Int J Endorsing Health Sci Res. 2013; 1 (2): 69-72.

25. Punjabi NM. The epidemiology of adult obstructive sleep apnea. Proc Am Thorac Soc. 2008; 5(2): 136-143. doi: 10.1513/pats.200709-155MG
26. Haile YG, Alemu SM, Habtewold TD. Insomnia and its temporal association with academic performance among university students: a cross-sectional study. BioMed Research International. 2017; 2017. Article ID 2542367. doi:10.1155/2017/2542367.

27. Jha R, Shah DK, Basnet $S$, Paudel KR, Sah $P$, Sah $A$, et al. Facebook use and its effects on the life of health science students in a private medical college of Nepal. BMC Res Notes. 2016; 9: 378. doi:10.1186/s13104-016-2186-0.

28. Perdereau-Noël M, Saliou P, Vic P. Prevalence of teenage sleeping disorder. Arch Pediatr. 2017; 24 (4): 336-45. doi: 10.1016/j.arcped.2017.01.009.

29. Azad MC, Fraser K, Rumana N, Faris A, Shahana $\mathrm{N}$, Hanly PJ, et al. Sleep disturbances among medical students: a global perspective. J Clin Sleep Med. 2015; 15; 11(1): 69-74. doi: 10.5664/ jcsm. 4370 .

30. Giri P, Baviskar M, Phalke D. Study of sleep habits and sleep problems among medical students of pravara institute of medical sciences Ioni. Ann Med Health Sci Res. 2013; 3(1): 51-54.

31. Ghoreishi A, Aghajani AH. Sleep quality in Zanjan university medical students. Tehran Univ Med J. 2008; 66(1): 66-71.

\begin{tabular}{|l|}
\hline AUTHOR AFFILIATION: \\
Dr. Saima Zainab (Corresponding Author) \\
Associate Professor \\
Department of Community Medicine \\
Liaquat National Hospital and Medical College \\
Karachi, Sindh-Pakistan. \\
Email: drsaimazainab@gmail.com \\
Prof. Rafiq Ahmed Soomro \\
Professor (Retired) \\
Department of Community Medicine \\
Liaquat National Hospital and Medical College \\
Karachi, Sindh-Pakistan. \\
Dr. Aneeta Khoso \\
Assistant Professor \\
Department of Community Medicine \\
Liaquat National Hospital and Medical College \\
Karachi, Sindh-Pakistan. \\
Dr. Nimra Aziz Qazi \\
Liaquat National Hospital and Medical College \\
Karachi, Sindh-Pakistan. \\
Dr. Saroop Siddiqui \\
Liaquat National Hospital and Medical College \\
Karachi, Sindh-Pakistan.
\end{tabular}

